\begin{tabular}{|c|c|}
\hline \multirow{3}{*}{ 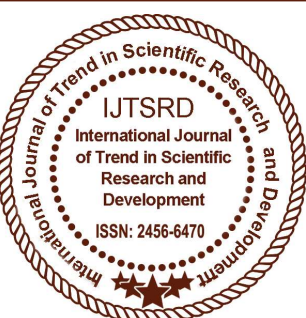 } & $\begin{array}{l}\text { International Journal of Trend in Scientific } \\
\text { Research and Development (IJTSRD) }\end{array}$ \\
\hline & Access Journal \\
\hline & ISSN No: 2456 - 6470 | www.ijtsrd.com | Volume - 2 | Issue -3 \\
\hline
\end{tabular}

\title{
Applicability of Brand Personality Scale in the Indian Context
}

\author{
Dr Anita Kshetri \\ Associate Professor, Kirloskar Institute of Advanced \\ Management Studies, Pune, Maharashtra, India
}

\author{
Dr Bidyanand Jha \\ Assistant Professor, Kirloskar Institute of Advanced \\ Management Studies, Pune, Maharashtra, India
}

\section{ABSTRACT}

In today's competitive market, brands have to strive to create a distinct differentiation for the competitive edge and survival. As the functional differentiation tends to lose the novelty for the consumers, marketers resort to symbolic differences. Brand personality addresses the symbolic function and symbolic benefit of the brand. Jennifer Aaker in her seminal research work constructed the brand personality scale which has been widely adopted for measuring brand personality. Although the scale developed by Aaker (1997) is most widely adapted scale in the brand personality research, the critical issue with the scale is the applicability in different cultural contexts. This paper investigates the applicability of the Brand Personality scale developed by Aaker in the Indian context. To test the applicability of the scale in entirety, 460 respondents were asked to measure the brand personality of their existing car and the preferred car by using the five-dimension Brand Personality Scale developed by Aaker (1997) as a framework. In the existing car brand personality, a 2factor structure with 13 item scale resulted, and in the preferred car, a 3-factor structure with 12 item scale resulted.

\section{Keywords: Brand, Personality, Brand Personality}

\section{INTRODUCTION}

"If you want to gain a deeper understanding of the quality of your brand's emotional relationships with consumers, most of the analogies with human relationships are worth exploring”.
McCrae (1996, p. 76)

Commoditization has become one of the key challenges with the marketers. In maturing markets where competition is intense consumers may view brands as the same, with little excitement to offer and minimal differentiation. Price may begin to be the differentiator, leading to a weaker foundation for loyalty (Aaker \& Joachimsthaler, 2000; Aaker, 2004). Brand differentiation is an important key in attaining a competitive advantage (Aaker, 2004). When not much product differentiation is present, the symbolic meaning and the experience becomes more crucial than what the brand can do functionally (Aaker \& Joachimsthaler, 2000; O'Shaughnessy \& O'Shaughnessy, 2004; Temporal, 2001).

Power (2008) says that branding is the strategic war of personifying the products. The use of brand personality in brand management strategies can help the whole company gaining satisfaction, loyalty, profitability (Rajagopal, 2006) and an overall economic advantage over its competitors (Park et al., 2005). When consumers are buying a brand which has a clarified personality in their minds, they are buying symbolic meaning associated with the brand rather than its physical product-related features. Researchers have claimed that brand personality is an important topic especially for differentiation and developing the emotional aspects of the brand and this concept has been well accepted by most advertising and marketing practitioners. (e.g Aaker, 1997; Bosnjak, 2007; D.Aaker, 1996, Diamantopoulos, 2004; Freling, 2005; Gupta, 2008; Park, 2005; Plummer; 1985). Features, benefits, services, or loyalty programs can be copied, but a distinct brand personality is an intangible differentiator that is specifically created, 
owned, and difficult to replicate (Aaker, 2004; Temporal, 2001).

Companies that employ brand personality as a part of an overall positioning strategy, when properly and consistently communicated, can affect consumer perceptions in far more enduring ways than other marketing and communication strategies (Burke, 1994). Brand personality becomes a key in differentiation, particularly in categories where products have reached functional parity and/or when symbolic consumption motivates market behavior. Consumers who want to enhance their sense of self are attracted to brands with distinctive and appealing personalities (Escalas and Bettman 2004; Swaminathan et al.. 2009; Park \& John , 2010).

With this aim, Aaker (19977) in her seminal work developed Brand Personality scale. Although the scale developed by Aaker (1997) is most widely adapted scale in the brand personality research, the critical issue with the scale is the applicability in different cultural contexts. As the scale has taken the lexical approach from psychology and is trait based, the traits are inferred in different ways and connotation in different countries and cultures (Kshetri et al, 2017). This paper explores the applicability of the brand personality scale developed by Aaker in the Indian context.

\section{Theoretical Background}

The first discovery of the Big Five was by Fiske in 1949 (Huang, 2009). However, it is the research done by Goldberg (1981) and McCrae and Costa (1985) among others that led to the contemporary Big Five. The Big Five theory of personality uses a lexical approach comprising personality attributes and trait descriptors which can be quantitatively analyzed in a hierarchical structure, that is, words and descriptors of personality traits/attributes are encompassed in a measurement instrument. The modern form of the Big Five model includes the dimensions of Openness, Conscientiousness, Extraversion, Agreeableness and Neuroticism (or OCEAN, which is the commonly used acronym). Though the labels of the five factors are slightly different from researcher to researcher, the content is more or less the same (Digman 1990, p.422-424).

Since the late 1950's, brands have been conceptualized as having a personality. Brands have been described in terms of human personality traits to help differentiate brands and increase the personal meaning of the brand to the consumer (Fournier 1998; Plummer 1984). Brand personality is now regarded as one of the core dimensions of the brand identity (D. Aaker, 1996). Consumers imagine the brands like human beings and give them personality characteristics; hence the dimensions of brand personality can be defined by extending the dimensions of human personality to the domain of brands (Rajagopal, 2006). Brand personality is used to describe brands as if they were human beings and is a term coined by practitioners who investigate consumers' perceptions towards the brands (Azoulay and Kapferer, 2003).

The early brand personality research used the scales and measures with little regard to validity and reliability. Kassarjian (1971), suggested, to achieve indisputable results across studies, researchers must develop their own scales and measures to reliably and validly measure the particular concepts and phenomenon under investigation. Aaker (1997) argued that brand personality operates differently than human personality and developed a framework of the brand personality construct with a set of indicators for measuring the construct dimensions. Based on the human personality model (Big five) Aaker (1997) did a seminal work in this field and found a new five dimensional model in the context of brands named Brand Personality Scale (BPS). Her work was the first step to generate a certain measurement personality model in the context of brand marketing. She solved the problem of reliability and validity the scale by offering a theoretical framework of brand personality on the basis of the "Big Five" human personality structure.

Aaker(1997) factor analyzes the individual ratings of 40 brands on 114 personality traits by 631 respondents recruited in the United States. The principal components factor analysis resulted in five significant factors. The BPS successfully met standards for internal reliability, test-retest reliability, content validity, nomological validity and construct validity (Aaker, 1997). The result of the exploratory principal component factor analysis yielded five distinct personality dimensions: Sincerity, Excitement, Competence, Sophistication, and Ruggedness. The "Sincerity" dimension captures the idea of a warm and accepting brand personality and represented by four facets: down-to-earth, honest, wholesome, and cheerful. "Excitement," similar to the human personality dimension extroversion, characterizes a sociable, energetic, and active brand 
personality, also represented by four facets: daring, spirited, imaginative, and up to date. The "Competence" dimension characterizes a brand personality that is responsible, dependable, and secure, represented by three facets: reliable, intelligent, and successful.

The brand personality dimensions correspond to three of the 'Big Five' human personality dimensions (Aaker, 1997). Agreeableness and Sincerity both capture the idea of warmth and acceptance. Extraversion and Excitement both include the notions of sociability, energy, and activity, while Conscientiousness and Competence both connote responsibility, dependability, and security. The other two brand personality dimensions Ruggedness and Sophistication differ from any of the 'Big Five' of human personality. According to Jennifer Aaker (1997), this pattern suggests these brand personality dimensions might operate in different ways or influence consumer preference for different reasons. Sincerity, Excitement, and Competence represent an innate part of human personality, whereas Sophistication and Ruggedness tap dimensions that individual's desire but do not necessarily have.

Cultural issues of brand personality have been studied by many researchers and in different countries by Aaker, Benet- Martinez, \&Garolera (2001); Sung \&Tinkham (2005); Bosnjak, 2007; Mendez, 2004 etc by replicating the scale development of Aaker's (1997) brand personality to other countries. However, they discovered that not all the five factors found by Aaker (1997) could be carried over to other countries. Aaker and colleagues (Aaker et al.. 2001) investigated the U.S., Japan, and Spain. Though the number of dimensions of brand personality extracted from the factor analysis was five in all three countries, some of the dimensions did not carry over to a different country. The three dimensions shared by these three countries were excitement, sincerity, and sophistication. Other dimensions (i.e. peacefulness, competence, and passion) were country-specific.

Similarly, Sung and Tinkham (2005) found that brand personality in the countries (U.S. and Korea) they surveyed included both common dimensions and cultural-specific dimensions. Individualist (Western Countries) subjects tended to use their preferred personality to project brand personality of their preferred brands; this was less true of their collectivist (Eastern Countries) counterparts (Phau and Lau, 2001). That is to say, the interpretation of the brand meaning must take into consideration the particular cultural lens through which the brand is being seen (Aaker et al., 2001). Cultures that are quite different in their values and needs (e.g., Western vs. East Asian cultures) are more likely to exhibit culture-specific differences in brand personality (Sung, 2005; Kshetri et al, 2016).

As there are constraints with the applicability of Aaker's Brand Personality Scale due to the cultural differences, it is essential to adapt the scale to the specific country/culture for managerial implications and future research work. Based on the theoretical background, following is the hypothesis developed for the study.

\section{Hypothesis: Brand Personality scale in entirety is applicable for Indian Consumer}

\section{Research Methodology}

\subsection{Research Design}

To address the research questions, a quantitative study was implemented. Data was acquired on the basis of convenience sampling. The samples were selected as the individuals who owned a car from the Pune city.The applicability of the brand personality scale in the Indian context was tested through two models (1) Owned car brand personality (OBP) where the consumers measured the brand personality of the present owned car and (2) Preferred car brand personality (PBP), where the consumers measured the brand personality of their new preferred car brand. In both the model the consumers described their present owned car and new preferred car on the brand personality scale developed by Aaker (1997). In the PBP model, the brands from different corporate brand and product classes in the passenger automobile car segment were used. The difference of the brands, design, conspicuousness, structure may influence brand evaluation, and hence brand personality. The brands were not assigned to the subjects as the subjects were free to choose their preferred brand in the product category.

A total of 610 self-administered questionnaire were collected out of which 460 questionnaire were used for the main study. Before running the analyses, data was checked for possible violations of the assumptions underlying factor analysis. A final usable sample of 460 was established after the data was screened for outliers, missing data, and normality and 435 samples were analyzed for factor analysis. 
The normality was tested using criteria suggested by George and Mallery (2003). According to it, skewness and Kurtosis between \pm 1 meet the assumption of normality. Each variable was tested for adequate skewness and kurtosis for the study. The respondents comprised $80 \%$ male respondents and $20 \%$ female. $73 \%$ of the respondents were between the age of $20-$ 40 years, and 58\% were having the household income more than Rs 5 lacs.

\subsection{Factor Analysis of Brand Personality}

As the indicators for the Brand Personality Scale were used in its entirety, an exploratory factor analysis was performed on the OBP (owned car brand personality) and PBP (Preferred car brand personality) data to test its appropriateness in measuring Brand Personality.

\subsubsection{Owned car brand personality (OBP)}

An exploratory factor analysis of 15 items (Down-toearth, Honest, Wholesome, cheerful, daring, Spirited, Imaginative, Up-to-date, Reliable, Intelligent, Successful, Upperclass, Charming, Outdoorsy, Tough) developed by Aaker (1997) was performed on the data collected from 435 sample size.

The Kaiser-meyer-Olkin measure of sampling adequacy was 0.912 , indicating that the present data and the correlations identified were suitable for principle component analysis. Similarly the Bartlett's Test of Sphericity was significant $p<0.001$ indicating sufficient correlations between the variables.

\section{Table 1: KMO and Bartlett's Test for OBP}

\begin{tabular}{|c|c|c|}
\hline Kaiser-Meyer-Olkin Measu & e of Sampling Adequacy. & .912 \\
\hline \multirow{3}{*}{$\begin{array}{l}\text { Bartlett's } \\
\text { Sphericity }\end{array}$} & Approx. Chi-Square & 3359.566 \\
\hline & Df natronal Journal & 78 \\
\hline & Sig.nd In Sclenthic & .000 \\
\hline
\end{tabular}

A total of 2 factors had eigenvalues greater than 1, eigenvalue also suggested two factors to be retained, cumulatively accounting for $63.55 \%$ of variance. The although the point of inflection was slightly below the scree plot which is the graphical representation of second factor.

\section{Figure 1: Scree Plot for OBP}

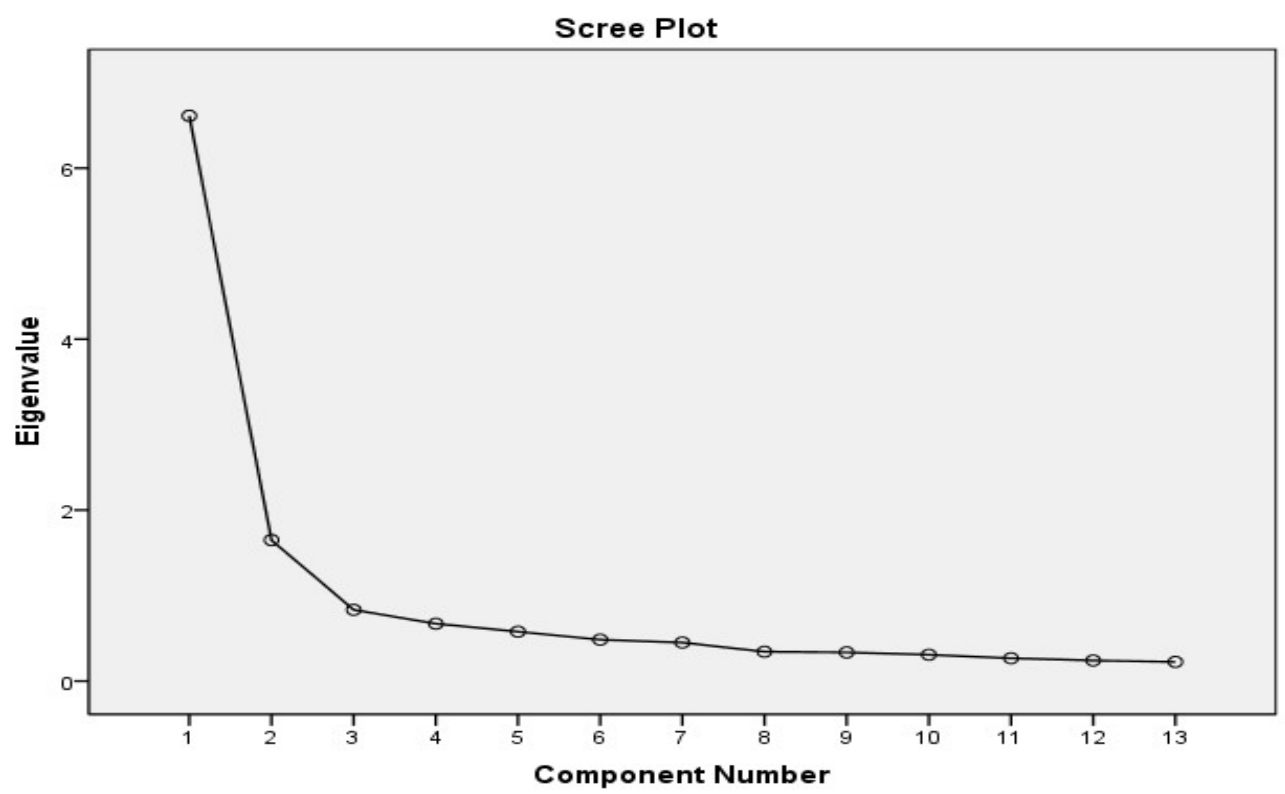

The factor rotation technique used was oblique factor rotation (Direct Oblimin).Since the component correlation matrix showed relationship between the two factors, oblique rotation generates two rotated matrix: Pattern Matrix and Structure matrix. The 
pattern matrix has been refereed to determine which variable load onto which factors.

From the pattern matrix it can be seen that Down-toearth, Honest, wholesome, cheerful, daring, reliable spirited have high co-efficient on factor 1, thus factor
1 can be named as Wholesome and Outdoorsy, Upperclass, Tough, Charming, Intelligent, Imaginative have high loading on factor 2 , thus factor 2 can be named as Upperclass.

Table 2: Pattern Matrix ${ }^{a}$ of OBP

\begin{tabular}{|l|l|l|}
\hline \multirow{2}{*}{} & Component \\
\cline { 2 - 3 } & 1 & 2 \\
\hline Down to earth & .904 & \\
\hline Honest & .885 & \\
\hline Wholesome & .830 & \\
\hline Cheerful & .712 & \\
\hline Daring & .595 & \\
\hline Reliable & .552 & \\
\hline Spirited & .510 & \\
\hline Outdoorsy & & .847 \\
\hline Tough & & .823 \\
\hline Charming & & .798 \\
\hline Upper class & & .788 \\
\hline Intelligent & & .498 \\
\hline Imaginative & & .471 \\
\hline
\end{tabular}

Extraction Method: Principal Component Analysis. Rotation Method: Oblimin with Kaiser Normalization

Table 3: Component Correlation Matrix of OBP

\begin{tabular}{|l|l|l|l|}
\hline \multicolumn{2}{|c|}{ Component } & \multicolumn{1}{|c|}{1} & \multicolumn{1}{c|}{2} \\
\hline $\mathbf{1}$ & & 1.000 & \\
\hline $\mathbf{2}$ & & .452 & .452 \\
\hline
\end{tabular}

Extraction Method: Principal Component Analysis. Rotation Method: Oblimin with Kaiser Normalization.

\subsubsection{Preferred car brand personality (PBP)}

An exploratory factor analysis of 15 items (Down-toearth, Honest, Wholesome, cheerful, daring, Spirited, Imaginative, Up-to-date, Reliable, Intelligent, Successful, Upperclass, Charming, Outdoorsy, Tough) developed by Aaker (1997) was performed on the data collected from 435 sample size.
The Kaiser-meyer-Olkin measure of sampling adequacy was 0.890 , indicating that the present data and the correlations identified were suitable for principle component analysis. Similarly the Bartlett's Test of Sphericity was significant $\quad \mathrm{p}<0.001$ indicating sufficient correlations between the variables.

Table 4: KMO and Bartlett's Test for PBP

\begin{tabular}{|l|l|l|}
\hline \multicolumn{2}{|l|}{ Kaiser-Meyer-Olkin Measure of Sampling Adequacy. } & .890 \\
\hline $\begin{array}{l}\text { Bartlett's Test of } \\
\text { Sphericity }\end{array}$ & Approx. Chi-Square & 3218.125 \\
\cline { 2 - 3 } & $\mathrm{df}$ & 66 \\
\cline { 2 - 3 } & Sig. & .000 \\
\hline
\end{tabular}




\section{Figure 4.2: Scree Plot of PBP}

A total of 3 factors had eigenvalues greater than 1, scree plot which is the graphical representation of cumulatively accounting for $72 \%$ of variance. The eigenvalue also suggested three factors to be retained.

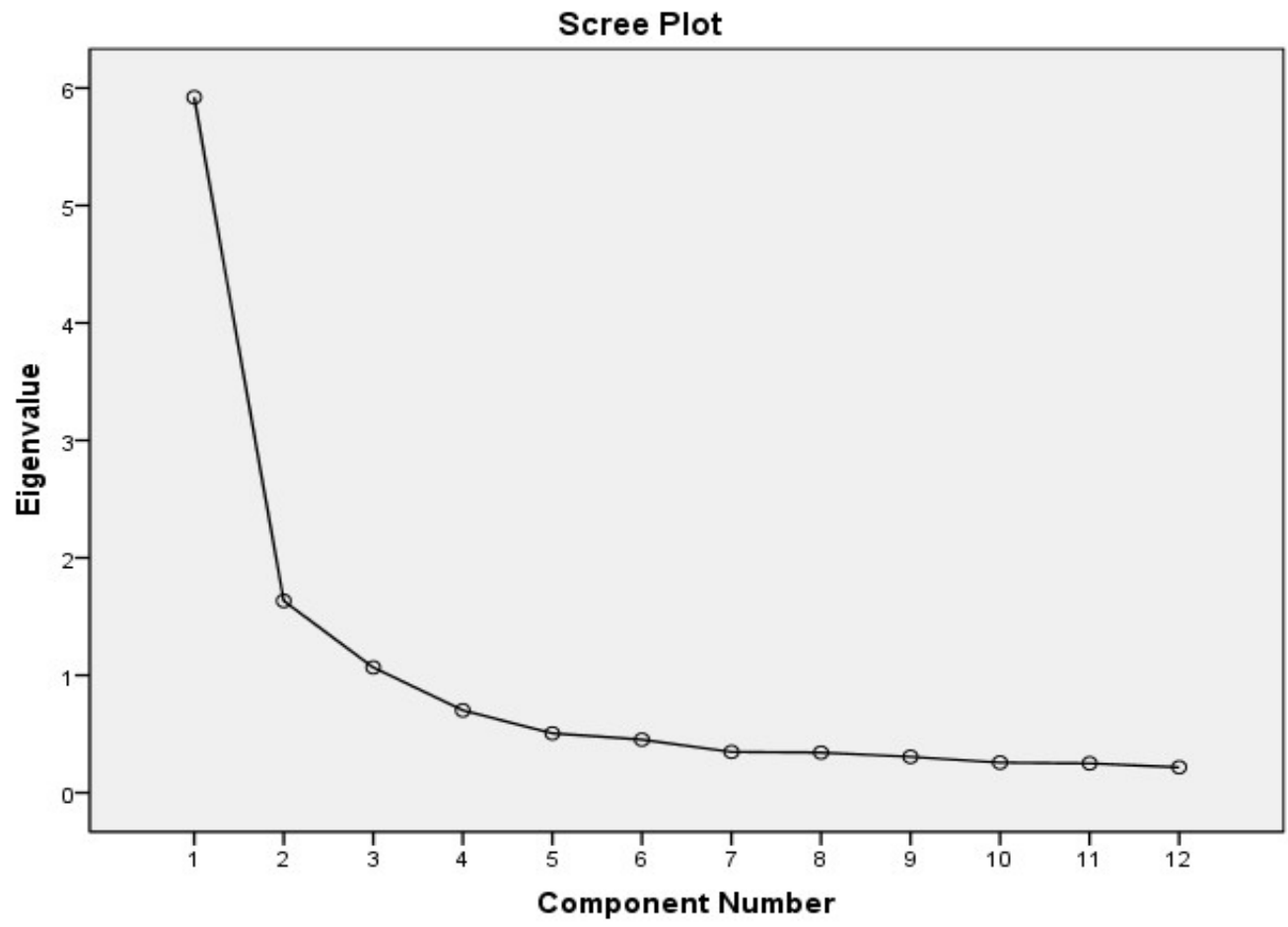

The factor rotation technique used was oblique factor rotation (Direct Oblimin). Since the component correlation matrix showed relationship between the two factors, oblique rotation generates two rotated matrix: Pattern Matrix and Structure matrix. The pattern matrix has been refereed to determine which variable load onto which factors.
From the pattern matrix it can be seen that Outdoorsy, Upperclass, Tough, Charming, Successful have high co-efficient on factor 1 , thus factor 1 can be named as Upperclass.Down-to-earth, Honest, Wholesome have high loading on factor 2 , thus factor 2 can be named as Sincerety.Imaginative, Spirited, daring, Up-to-date have high loading on factor 3 , thus factor 3 can be named as Excitement.

Table 5: Pattern Matrix ${ }^{\mathrm{a}}$ for PBP

\begin{tabular}{|c|c|c|c|}
\hline & \multicolumn{3}{|c|}{ Component } \\
\hline & 4 & 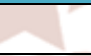 & 3 \\
\hline Outdoorsy & .883 & & \\
\hline Upperclass & .816 & & \\
\hline Tough & .799 & & \\
\hline Charming & .788 & & \\
\hline Successful & .766 & & \\
\hline Down to earth & & .959 & \\
\hline Honest & & .825 & \\
\hline Wholesome & & .664 & \\
\hline Imaginative & & & -.865 \\
\hline Spirited & & & -.817 \\
\hline Daring & & & -.772 \\
\hline Up-to-date & & & -.706 \\
\hline
\end{tabular}

Extraction Method: Principal Component Analysis. Rotation Method: Oblimin with Kaiser Normalization.

a. Rotation converged in 8 iterations. 
Table 6: Component Correlation Matrix for PBP

\begin{tabular}{|l|l|l|l|l|}
\hline \multicolumn{2}{|l|}{ Component } & 1 & 2 & 3 \\
\hline & 1 & 1.000 & .345 & -.526 \\
\cline { 2 - 5 } & 2 & .345 & 1.000 & -.462 \\
\cline { 2 - 5 } & 3 & -.526 & -.462 & 1.000 \\
\hline
\end{tabular}

Extraction Method: Principal Component Analysis.

Rotation Method: Oblimin with Kaiser Normalization.

\section{FINDINGS AND CONCLUSION}

The brand personality scale developed by Aaker (1997) could not be applied in its entirety in the study. The study involved two models for measuring the brand personality congruence. The first model examined the existing owned car brand personality (OBP) and the second model involved a new preferred car brand personality (PBP).

The OBP model resulted a 2-factor structure, stable 13 item scale with a 2-factor solution: Wholesome (Down-to-earth, Honest, wholesome, cheerful, daring, reliable spirited) and Upperclass (Outdoorsy, Upperclass, Tough, Charming, Intelligent, Imaginative).The PBP model resulted in a 3-factor structure, stable 12 item scale with a 3 -factor solution :Upperclass (Outdoorsy, Upperclass, Tough, Charming, Successful), Sincerity (Down-to-earth, Honest, wholesome) and Excitement (Imaginative, Spirited, daring, Up-to-date).

In both the models the 15-items-5-dimesions scale could not be retained for the Indian consumer's context. Hence we reject the hypothesis that Brand Personality scale in entirety is applicable for Indian Consumer. The scale has to be modified for further application.

\section{Limitations and Future Research}

In this research, the model was tested using only the automobile passenger car because cars are high in conspicuousness (therefore are likely to be evaluated using symbolic criteria).However the scale must be tested for other product classes and categories to test the applicability of the scale. The brand personality can have various moderating variables and mediating variables (Rodriguez et al., 2012) like level of involvement, country of origin (Wang \& Yang, 2008) ,brand identification (Kuenzel, 2010), product usuage (Khan \&Bozzo, 2012), attachment styles (Swaminathan et al., 2009), which has not been included in this study. The moderating and mediating effect can be further studied with the help of this study in the Indian context.

The sample was drawn from Pune city which is a cosmopolitan metro city, the income, education level and the occupation of the samples might not be extrapolated to other smaller town or rural location. This geographic limitation in this study can be researched further by encompassing a larger geographic location as to actually ascertain the real view of the Indian consumers.

\section{REFERENCES}

1. Aaker, D. (1996). Building strong brands. New York: The Free Press.

2. Aaker, D., \&Joachimsthaler, E. (2000). Brand leadership. New York: Free Press.

3. Aaker, J. L. (1997). Dimensions of brand personality. Journal of Marketing Research, 34(3), 347-356.

4. Aaker, JL, Benet-Martinez, V and Garlolera J. (2001). 'Consumption Symbols as Carriers of Culture: A Study of Japanese and Spanish Brand Personality Constructs'. Journal of Personality and Social Psychology, 81(5), 492-508.

5. Aguirre-Rodriguez, A., Bosnjak, M., \&Sirgy, M. J. (2012). Moderators of the self-congruity effect onconsumer decision-making: a meta-analysis. Journal of Business Research, 65, 1179-1188.

6. Azoulay, A., \&Kapferer, J. (2003). Do brand personality scales really measure brand personality? The Journal of Brand Management, 11(2), 143-155.

7. Burke, B. (1994). Position, personality, not price, should frame consumer messages. Brandweek, 35, 36. 
8. Diamantopoulos, A., Smith, G., \& Grime, I. (2005). The impact of brand extensions on brand personality: Experimental evidence. European Journal of Marketing, 39(1/2), 129-149

9. Digman, John M. (1990). "Personality Structure: Emergence of the Five-Factor Model" . Annual Review of Psychology, 41, 417-440.

10. Escalas, JE . (2004).Narrative Processing: Building Consumer Connections to Brands. Journal of Consumer Psychology, 14(1/2), 168180.

11. Fournier, S. (1998). Consumers and their brands: Developing relationship theory in consumer research. Journal of Consumer Research, 24(4), 343-373.

12. Freling, T . H .and Forbes , L . P .(2005). An empirical analysis of the brand personality effect . Journal of Product and Brand Management 14 (7) : $404-413$.

13. George, D. and Mallery, P. (2003) SPSS for Windows Step by Step: A Simple Guide and Reference. 11.0 Update. 4th Edition, Allyn \& Bacon, Boston

14. Gupta, S., S. Grant, et al. (2008). "The expanding role of intangible assets of the brand." Management Decision 46: 948-960.

15. Kassarjian, H. (1971). Personality and consumer behavior: A review. Journal of Marketing Research, 8, 409-18.

16. Khan M. and Bozzo C. (2012). Connection Between Self-concept and Brand Preference and theRole of Product Usage.International IJAS Conference,Lasvegas,USA.

17. Kuenzel Sven. (2010). The chain of effects from reputation and brand personality congruence to brand loyalty: The role of brand identification. Journal of Targeting, Measurement and Analysis for Marketing Vol. 18, 3/4, 167-176.

18. McCrae, Robert R. and Paul T. Costa, Jr. (1996). "Toward a New Generation of Personality Theories: Theoretical Contexts for the Five-Factor Model," in The Five-Factor Model of Personality: Theoretical Perspectives, by Jerry S. Wiggins (Ed.), New York: The Guilford Press, 51-87.

19. McCrae, Robert R. and Paul T. Costa, Jr. (1985) ."Updating Norman's "Adequate Taxonomy": Intelligence and personality Dimensions in Natural Language and in Questionnaires". Journal of Personality and Social Psychology, 49 (3), 710721.
20. O'Shaughnessy, J., \& O'Shaughnessy, N.J. (2004). Persuasion in Advertising. New York: Routledge.

21. Park J1 Kyung \& John Deborah Roedder. (2010). Got to Get You into My Life: Do Brand Personalities Rub Off on Consumers?, Journal Of Consumer Research, Vol. 37

22. Park S.Y. and Lee E.M. (2005). Congruence between brand personality and self-image, and the mediating roles of satisfaction and consumerbrand relationship on brand loyalty. Asia-Pacific Advances in Consumer Research, Vol 6.

23. Phau, I., \& Lau, K.C. (2001). Brand personality and consumer self-expression: Single or dual carriageway? Journal of Brand Management, 8, 6, 428-444.

24. Plummer J. T. (1984). How personality makes a difference .Journal of Advertising Research 24 (6) $: 27-31$.

25. Plummer, J.T. (1985) . How personality makes a difference. Journal of Advertising Research, 24, 6, 27-31.

26. Power, D. and A. Hauge. (2008). No Man's Brand-Brands, Institutions, and Fashion. Growth and Change 39: 123-143

27. Rajagopal.(2006). Insights from research Brand excellence: measuring the impact of advertising and brand personality on buying decisions. Measuring Business Excellence.

28. Sung, Y and Tinkham, SF. (2005). Brand Personality Structures in the United States and Korea: Common and Culture-Specific Factors. Journal of Consumer Psychology, 15(4), 334-350.

29. Swaminathan, Vanitha, Karen M. Stilley, and Rohini Ahluwalia. (2009). When Brand Personality Matters: The Moderating Role of Attachment Styles. Journal of Consumer Research, 35 (April), 985-1002.

30. Temporal, P. (2001). Branding in Asia: The creation, development and management of Asian brands for the global market. Singapore: John Wiley \& Sons (Asia) Pte Ltd.

31. Wang Xuehua\& Yang Zhilin. (2008). Does country-of-origin matter in the relationship between brand personality and purchase intention in emerging economies?. International Marketing Review, Vol. 25 No. 4. 